\title{
Fabular un pueblo a través del arte
}

\section{Fabulando uma cidade através da arte}

\section{Fabulating a town through art}

\author{
Ángela María Chaverra Brand*
}

\begin{abstract}
RESUMEN
Este escrito es derivado del proceso de investigación: "La fabulación: acción y conceptualización en la relación arte y pedagogía”, que actualmente realiza el Colectivo Artístico El Cuerpo Habla; este retoma el concepto de fabulación, propuesto por Henry Bergson, y, luego, actualizado por Guilles Deleuze, quien hace un despliegue del término como la posibilidad de fundar actos de habla en la comunidad a través del arte, lo que permite una expansión de la estética hacia una dimensión política.
\end{abstract}

Palabras clave: Fabulación. Arte. Performance. Pedagogía.

\section{RESUMO}

Este texto é derivado do processo de pesquisa: “A fabulação: ação e conceitualização na relação arte e pedagogia" que atualmente é realizado pelo Coletivo Artístico El Cuerpo Habla, no qual se retoma o conceito de fabulação que propõe Henry Bergson desde a religião e que posteriormente foi atualizado por Guilles Deleuze, no desdobramento do termo como possibilidade de fundar atos de fala na comunidade através da arte, o que permite uma expansão da estética para uma dimensão política.

Palavras-chave: Fabulação. Arte. Performance. Pedagogia.

\footnotetext{
ABSTRACT

This writing is derived from the research project: "Fabulation: action and conceptualization in the relation between art and pedagogy," which is currently being carried out by the artistic collective El Cuerpo Habla, which

* Universidad de Antioquia. Facultad de Artes. Medellín, Antioquia, Colombia. e-mail: angela.chaverra@udea.edu.co.http://orcid.org/0000-0001-7789-2930
} 
evokes the concept of fabulation, proposed by Henry Bergson, and which was later updated by Guilles Deleuze, who clarified the term as a possibility of founding acts of speech in the community through the medium of art, which allows an expansion of aesthetics into a political dimension.

Keywords: Fabulation. Art. Performance. Pedagogy.

\section{FIGURA 1 - DESEO Y FABULACIÓN}

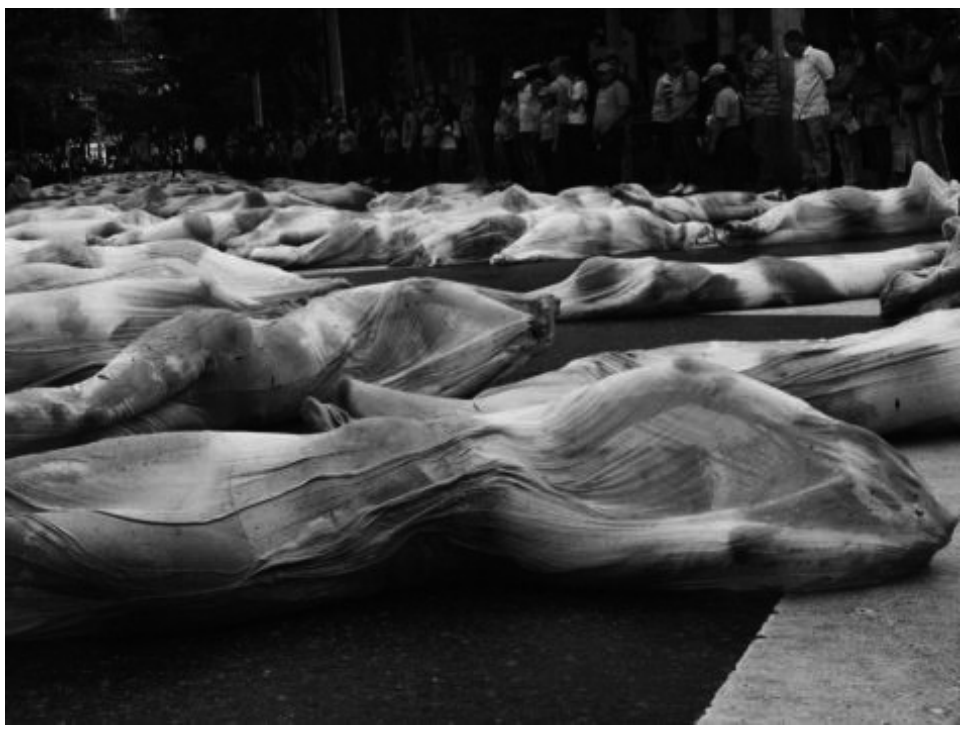

FONTE: Performance "Vadear". Colectivo Artístico El Cuerpo Habla. Medellín, Colombia 2011. Fotografía: Reinel Arango

El devenir artista de quien escribe empezó con la pregunta por el deseo, la cual se generó desde una formación psicológica con tendencia psicoanalítica: ¿Qué se desea? El deseo según el psicoanálisis es un deseo de deseo, no tiene un objeto que lo ate, se desplaza, es erótico, inconcluso, paradójico, metonímico y efímero. Como motor de vida actúa y se encarna. Dice Lacan que, el deseo es causa de deseo, dada la pérdida de su objeto, abierto y pulsante.

El deseo no se fija en un significante, se mantiene la resistencia de la significación en un desplazamiento constante; por lo tanto no puede asirse a un objeto o nombrarse como categoría. Más que instalarse, el deseo actúa, determinando el destino del sujeto; es una fuerza que persiste, insiste y resiste. Lo que puede ampliar el camino del deseo, según Lacan, es la tragedia de Hamlet. Dice el autor que el arte desbroza el camino para el psicoanálisis; la lectura que hace 
del personaje de Shakespeare permite ver cómo éste queda atrapado en el deseo del padre y no puede vivir su propio destino, sino su propia tragedia a partir de un mandato extremo: "Hay algo que no va en el deseo de Hamlet" (Lacan, 2015, 302). Así, a través del estudio de Hamlet, Lacan evidencia cómo el deseo es paradójico; afirma, por ejemplo, que en la neurosis el deseo no se satisface, se fija parcialmente en una palabra o en una representación; por ello, el deseo es "la metonimia de la falta en ser en la que se sostiene." (Lacan, 2009, 594).

El deseo encarnado en la figura de Hamlet ha dado al arte un lugar visionario. La verdad de la muerte del padre, se revela, de manera contundente, a través de una escena teatral (el teatro en el teatro), lo que permite afirmar que la creación artística facilita la reflexión sobre lo humano y el entendimiento de lo trágico en la vida de los hombres. El arte, dice Lacan, teje alrededor de un vacío. De allí que Hamlet admite decir que el deseo se instaura sobre una falta, la falta en ser. "Ser o no ser."

La fuerza del arte, en las relaciones vanguardistas que establece con otros saberes, en este caso con el psicoanálisis, se perfila de manera más contundente en el siglo XX. Para la segunda mitad de ese siglo, muy ligados al psicoanálisis, aparecen Foucault, Deleuze, Guattari, entre otros, quienes critican fuertemente el escenario de sublimación en el que se coloca el arte en la teoría de Freud, de la cual se han derivado ciertos planteamientos en las maneras como las comunidades, los críticos y artistas ven el problema de la estética. Además de una réplica a la construcción del concepto de deseo desde la falta en ser, lo cual se vuelve el centro de esta disertación, esos autores, y muy especialmente Deleuze, concentran la mirada en pensadores como: Henry Bergson, Spinoza, Nietzsche, Artaud, para coincidir en la necesidad de expandir los conceptos que por tanto tiempo han sido categóricos y han obedecido a una construcción positivista del mundo.

El encuentro con Henry Bergson, premio Nobel de literatura, a través de su texto La evolución creadora, le permite a Deleuze desplegar el concepto de fabulación del cual el Colectivo Artístico El Cuerpo Habla, ha hecho uso para entender y presentar su propuesta artística. Este término, fabulación, es acuñado por Bergson para referirse a la importancia de la construcción social que hace resistencia a la inteligencia, ya que esta aumenta el egoísmo y la división. El autor, a través de una comparación entre el instinto animal y el humano, dice que en el hombre se da de manera virtual o latente, tal como se ve en la religión, diferenciándolo de los animales, ya que en estos ese instinto es automático.

La función fabuladora consolida la sociedad involucrando a los individuos en la fabricación de espíritus y dioses. La inteligencia, al ser individual y egoísta, entra en contradicción con la naturaleza, porque a partir de su individualización puede fragmentar el todo social; por ello, frente a este peligro, aparece un 
instinto de orden virtual, que es capaz de crear representaciones imaginaras de tipo religioso. La inteligencia y el instinto virtual se corresponden de tal manera que el instinto es un residuo que subyace alrededor de la inteligencia y en el instinto resplandece un brillo de inteligencia. El instinto, a pesar de pertenecer a la inteligencia, tiene la función de restablecer el orden natural, a través de una primera instancia que es la religión estática, que establece una moral cerrada o primitiva, más del orden de la superstición. Sin embargo, no se queda allí y crea una segunda instancia que es la religión dinámica, la cual tiene fe en la humanidad y se basa en las relaciones sociales, en el mismo concepto divino, más del lado del misticismo, que es lo que verdaderamente sostiene a la sociedad, "comunicando el esfuerzo espiritual que manifiesta la vida" (Hernández, 2001, 99), y, por ende, un instinto de conservación, reactivo y de resistencia, que actúa para no perder la cohesión social. Entonces, se podría decir que el instinto virtual es creador.

La fabulación, así, ayuda a conservar la sociedad humana a través de la religión natural. El hombre no abandona completamente el instinto perdido, porque permanece en él en estado de virtualidad (instinto virtual). La función fabuladora se convierte en un dispositivo natural capaz de enfrentar el trabajo intelectual. Sin ser más un instinto, desempeña en las sociedades humanas un papel simétrico al del instinto en las sociedades de los insectos.

A través de la religión se crea una defensa contra el poder de la inteligencia y del pensamiento que solo busca el beneficio propio. El ejercicio de pensar lleva al individuo a disolver y alejarse del tejido social, por lo que hace uso de la religión como una "reacción defensiva de la naturaleza contra la representación que hace la inteligencia de la inevitabilidad de la muerte." (Zunino, 2012, 13). Si bien, prosigue Bergson (1948), la muerte es extrema, hay otros pormenores que afectan al hombre, y la inteligencia hace una representación de un margen desalentador frente a lo inesperado abriendo un orificio por el cual se cuela la angustia de lo humano, por lo que la fabulación se vuelve no solo una resistencia contra el egoísmo, contra la muerte, sino también contra este margen desalentador provocado por la inteligencia.

Es la fuerza de la fabulación la que denota una "voluntad de tener éxito" (Zunino, 2012, 15) y ayuda a establecer una semejanza entre la mentalidad del hombre civilizado y la del primitivo, sobre todo con respecto a la muerte, la enfermedad y el accidente. La diferencia es que este no cree en el azar: para él, nada ocurre porque sí, porque se tiene buena o mala suerte, sino porque alguna "fuerza activa" está presente. Por eso tiende a sentirse víctima del hechizo de una bruja y busca protegerse con amuletos.

Para Bergson la diferencia entre el hombre primitivo y el civilizado, con respecto a la fabulación, es que el primero cree en la magia, es más pasivo, porque 
está sometido a estos poderes externos, en tanto el segundo se encuentra en una instancia más "evolucionada", que equivale a creer en fuerzas dinámicas, en la presencia de deidades, lo que establece grados: la magia trabaja con entidades imprecisas (fuerzas, fantasmas o espíritus), mientras que la religión celebra cultos a dioses y divinidades y está a favor de formar comunidades a través de una representación que resiste, es reactiva, tiene fe en la comunidad, combate la intelectualidad, así, la gente se relaciona creando un pacto social unido ante un peligro. De este corte dinámico es la función fabuladora, pues su mayor objetivo es cohesionar la sociedad a través de una representación religiosa. La intelectualización del dinamismo de la fabulación, sea religiosa o mágica, vuelve estática la vida, aparta el conocimiento y la acción, reduce la vitalidad. "Antes de filosofar es preciso vivir", sentencia Bergson (Zunino, 2012, 11).

Debido a que la inteligencia trabaja a partir de representaciones, de percepciones presentes y recuerdos que son residuos de imágenes perceptivas, la función fabuladora puede suscitar en ella representaciones imaginarias que contrarresten el trabajo intelectual, reorientándolo hacia la preservación de la vida y, asegurando, sobre todo, la cohesión social; así, estas percepciones ilusorias serán lo bastante precisas para que la inteligencia logre determinarse por ellas, las imitará impidiendo o modificando la acción.

\section{La fabulación en Deleuze}

Deleuze recoge de Bergson las nociones de fabulación y de instinto virtual como creador, y despliega esta trama para encontrar resonancias con los conceptos de deseo, arte y máquina social; sin embargo, da un giro a varias de las declaraciones de Bergson. Uno tiene que ver con la religión, puesto que el concepto de fabulación lo aplica al arte, y descarta lo religioso de este contexto. Hace un paralelo con Bergson al afirmar que el arte no funda conceptos, apartándose, como él, de la inteligencia en el sentido de entidad principal en la producción artística. El arte crea bloques de sensaciones como afectos y perceptos. La filosofía instaura conceptos, pero no desde la reflexibilidad, sino a través de un acto creador, porque los conceptos no son estáticos, se mueven construyendo planos de inmanencia. La ciencia produce funciones de manera análoga. Así, la filosofía, el arte y la ciencia mantienen relaciones de mutua resonancia en cuanto son procesos de producción.

Otra distancia que toma Deleuze con respecto a los planteamientos de Bergson es acerca del tema de la fabulación como fuerza reactiva; para Deleuze 
la fabulación es resistencia, pero no reactiva, sino creadora, propositiva; en este sentido se acerca más a Nietzsche quien afirmaba que hay fuerzas reactivas y fuerzas activas. Las activas tienen el poder de la transformación, afirmación diferencial, son potencias, pueden adquirir nuevas formas; las reactivas tienden a la conservación, adaptación y supervivencia.

Deleuze, así mismo, parte del concepto de la fabulación para hablar del deseo y oponerlo al expuesto por el psicoanálisis, que lo ve desde lo individual y la falta en ser. Deleuze y su compañero intelectual Guattari, se refieren al deseo como la construcción de una sociedad, revolución de máquinas deseantes que emergen de una comunidad; la producción de una máquina deseante se da en la presencia de un pueblo y en ese sentido la función del arte posibilita esta fábrica de deseos, a partir de acontecimientos que desembocan en actos de habla comunitarios, lo cual permite una movilización política. De esta manera, el arte $\mathrm{y}$ el deseo convergen en un encuentro de fuerzas activas.

El deseo es producción, movilización, voluntad de poder, afecto activo, tal como lo plantean Spinoza y Nietzsche; y Deleuze y Guattari hacen eco de ello. El deseo es revolucionario porque crea sus propios objetos; en cambio, desde la concepción del deseo como falta, se fortalecen los sistemas de dominación, puesto que estos administran la escasez, la necesidad, haciendo que la población sea más esclava de sus carencias. Desde la óptica deleuzeana se propone una transformación en las instituciones, en las estrategias, moleculizar, romper las domesticaciones. A esto se le añade que si la inteligencia está caracterizada por una incomprensión de la vida, hay que oponérsele, hacerle resistencia a través de la función fabuladora, que se gesta como el deseo no de una persona, sino de una comunidad, enriqueciendo la capacidad de armar mundos alternos al que se ha establecido como realidad. Desde la perspectiva deleuzeana, el arte tiene la tarea de la fabulación, como un llamado a un pueblo que no existe todavía, siendo ese pueblo una producción de deseo o, mejor aún, el deseo es producción social. El deseo social se carga de energía libidinal, expansiva, molecular; volviéndose una potencia que resiste, porque crea conexiones, intensidades; por ello no se uniforma ni se liga a objetos fijos, porque estos se vuelven construcciones molares, duras.

Es aquí, en el lugar del deseo, de la fabulación y la llamada al pueblo, donde aparece, para El Colectivo Artístico El Cuerpo Habla, una pieza fundamental en la reflexión de su hacer artístico, pedagógico, ético y político, que tiene que ver con la ruptura de la codificación, la imposibilidad de la clasificación en estándares regulados. El sistema, diría Deleuze, tiende a homogeneizar el deseo, interpretarlo y representarlo, hasta hacerlo consciente, incluso a través de un objeto (que puede ser una obra de arte). Además, a través de la uniformidad se codifica el deseo y se fija el sujeto a una identidad. La propuesta de estos autores (Deleuze y Guattari) es dislocar los conceptos molares de sujeto, objeto y otros 
más, como categorías cerradas. La noción de sujeto sugerida por ellos, se aleja de la identidad cerrada y se presenta como multiplicidades, subjetividades, que se transforman por los acontecimientos que las atraviesan, dando lugar a una diferencia de intensidades lo cual crea una singularidad más que una categoría. Cada intensidad es diferente y se da por acción de la exterioridad en ese pliegue de subjetividad. Los acontecimientos son las acciones de la exterioridad sobre los cuerpos, los cuales transforman los agenciamientos, según Deleuze, o los dispositivos según Foucault, de esas subjetividades. Las subjetividades circulan, y se arman máquinas deseantes, siempre encajándose y desencajándose, territorializando o desterritorializando.

En ese sentido, la propuesta artística y pedagógica-del colectivo-derivada de estos planteamientos es la de "crear" acontecimientos que movilicen los dispositivos o los agenciamientos. No se garantiza que esta sea una solución al malestar que vive la sociedad, pero hay la intención de abrir espacios para actos éticos, de resistencia política, que ayuden a dinamizar las relaciones y por ende los deseos de una comunidad; $y$, de paso, se proponen estrategias contemporáneas en las relaciones sociales, ya que el deseo se pliega a la gran masa social (molarizada), en aras de encontrar una salida. Si se logra encontrarla, se torna micro, polivalente, múltiple (molecular). Inventa, "crea", revoluciona, transgrede, dice Esther Diaz (En: http://www.estherdiaz.com.ar/textos/deleuze.htm).

También, según el concepto de fabulación desde la visión de Deleuze, se afirma la potencia de lo falso. Se trata de crear verdades más que de dar verdades por hechas y, en ese sentido, el arte no aspira a lograr el ideal de la verdad, sino a la presencia de múltiples presentes "incomposibles", como diría el autor, una transformación constante, que permite el devenir. La narración no anhela lo verdadero sino que se hace lo esencialmente falsificante, es decir, la potencia de lo falso deja de lado las apariencias y pone más bien fuerzas o intensidades. La verdad, más que alcanzada, debe jugar a ser creada para transformar el punto de vista fijo de las cosas y crear así un devenir. La opción es liberar a la ficción de la categoría de verdad creada por occidente, para encontrar la función de la fabulación, hacerse otro y constituir una imagen-tiempo. El devenir, la imagen-tiempo, pertenecen a un pueblo, una minoría a la que se le ha negado la palabra. En ese sentido, la fabulación es un acto político, diferente a la ficción. La ficción pertenece, según Deleuze, a la palabra del amo. La fabulación se convierte en una fuerza activa, creadora, que deja de lado lo reactivo por oposición y respuesta, y logra un acto de habla, es decir, crea.

La narración falsificante que le corresponde da un paso más, y plantea en presente diferencias inexplicables y en pasado alternativas indecidibles 
entre lo verdadero y lo falso. El hombre verídico muere, todo modelo de verdad se derrumba, en provecho de la nueva narración. No hemos hablado de quién al respecto es el autor capital, Nietzsche, quien bajo el nombre de "voluntad de potencia" sustituye la forma de lo verdadero por la potencia de lo falso, y resuelve la crisis de la verdad, quiere liquidarla de una vez por todas pero, contrariamente a Leibniz, en provecho de lo falso y de su potencia artística, creadora... (Deleuze, 1987, 177-178).

La crisis de verdad es lo que le da fuerza a la fabulación y ello convoca a una comunidad a crear un acto de habla divergente. Es la invitación a ser manada en la que se encuentran los intercesores, quienes son medios de expresión, detonadores del pensamiento creativo, alejados de los conceptos ideales de verdad, belleza y bondad. Dice Deleuze que sin el intercesor no hay obra. Los intercesores pueden ser cosas, animales o personas, reales, imaginarios, una serie; hay que tenerlos porque el trabajo siempre es en grupo. "Tanto más cuando no lo es: Félix Guattari y yo somos intercesores el uno del otro." (Deleuze, 1995, 107).

El cuestionamiento de los preceptos por los que se ha regido la humanidad, implica un giro conceptual, ético, estético, incluso un cambio de percepción de lo que se ha llamado público. El legado de un término como el de intercesor pone en cuestión la idea de una distancia entre el artista y el otro. Si el arte, como dice Deleuze, es una llamada a un pueblo que no existe todavía, ese pueblo más que una entidad apartada de la relación con el arte, funda una comunidad, una intercesión o, utilizando el término del profesor de teatro Jorge Dubatti, "un convivio" lo que genera una mirada diferente de la crítica artística, la cual ha juzgado las obras y a los artistas a través de modelos cerrados de un deber ser del arte y un comportamiento del espectador. La función de la fabulación se da dentro de una comunidad como lo presenta Bergson; es necesario otro que fabule y en esa medida cumple el rol de intercesor, para que juntos funden un acto de habla desde la divergencia, un discurso minoritario, lo que equivale a crear un pueblo que no preexiste, que falta. Dice Paul Klee que el pueblo es el que falta, pero que aparece en las acciones de resistencia, en la capacidad de crear manada, de enunciarse de maneras diferentes a como lo han hecho los amos del mundo, de reconocerse desde la diferencia y la exclusión, lo cual permite salir de las clasificaciones a través de un gesto que se vuelve un grito (DELEUZE, 1987). El grito de Nietzsche: un grito devenir humanidad, pero también devenir animal y devenir mundos, imperceptible e intenso, disolver las categorías y, por tanto, disolver el sujeto, para ser siempre otro. 
Un intercesor puede ser cualquier cosa. Lo clave es que nos permiten dejar de lado el discurso colonizador, en primera persona, mayoritario y oficial; liberando al mismo tiempo el discurso impersonal, minoritario y subversivo. Nos ofrecen, entonces, la posibilidad de encontrar vías de escape o líneas de fuga para poder huir de toda forma de control y para crear, al mismo tiempo, nuevas conexiones, agenciamientos antes inimaginables, logrando con ello pensar lo impensado, decir lo indecible y vivir lo invivible. Es quien nos permite liberar las fuerzas impersonales que nos conforman, esto es, las singularidades que nos pueblan pero que normalmente son desplazadas de la representación consciente que tenemos de nosotros mismos, es decir, reprimidas. (Bustamante, 2010, 109).

\section{El Cuerpo Habla}

El Colectivo Artístico El Cuerpo Habla, haciendo eco del concepto de fabulación, ha creado un campo de estudio para entender los alcances del mismo, la manera en que influye en los discursos artísticos, éticos, políticos, pedagógicos, de los integrantes del colectivo, y su resonancia en el contexto que lo circunda, a través de la investigación: "La fabulación: acción y conceptualización en la relación arte y pedagogía", la cual ha permitido expandir los límites de su propuesta artística, la producción de conocimiento y las maneras en que se relacionan los saberes propios con los de la comunidad a quien se dirige.

Se elige trabajar en equipo desde la propuesta de los autores: Bergson, Deleuze, Guattari y otros, poniendo a prueba el gesto de fundar manada, colectividad, el pueblo que se crea a través de prácticas de resistencia e intercesión. Para ello, el colectivo se vale de un dispositivo como la performance o, lo que se ha llamado, acciones de la carne, que integra singularidades más que sujetos, problematizan los conceptos de cuerpo, arte, estética, representación, y vinculan el arte con la política en un ejercicio de expandir sus límites. Al evaluar las últimas performances (2015 -2017): "Carga-montón", "In-movedizo", "Terrar", "Hervir", "Con guerra no brazos" (porque ya de algunas otras se ha hablado en otros escenarios), se tienen en cuenta varios aspectos: el colectivo, el espacio, el proceso, la comunidad, los cuerpos de los participantes y las problemáticas de la ciudad y del país. "Carga-montón”, por ejemplo, es una hechura de los retazos de otros cuerpos; se estrena en 2015, después de ganar el Premio Nacional de Arte Sara Modiano, en Colombia. Se origina desde la reflexión sobre el maltrato a los cuerpos, el ensañamiento con las maneras de tortura en países como los nuestros: Colombia, México, Brasil y otros; la historia de las muertes, los 
cadáveres que se tiran a los mares, ríos y a las fosas comunes o que se exhiben insensiblemente en las calles.

Se partió de la idea de una carreta para transportar los cuerpos de tal manera que amalgamaran y pudieran fundirse al poner en escena la noción de cuerpo sin órganos, propuesta por Deleuze, pensando, además, que a través de la historia de Colombia y del mundo se ha utilizado la carreta para cargar a los muertos; es cierto que ella también ha acarreado vida, sin embargo en las épocas de la peste y la violencia, este medio de transporte ha servido no solo para arrastrar, sino para amontonar los cuerpos inertes.

Decía Gabriela (la joven del colectivo que coordinó todo el proyecto) que, solamente era posible moverse si todos se movían al mismo tiempo, como en una oleada y cuando el dolor del otro se convertía en el propio. En esta performance se logró una buena sincronía, afirmar la vida, establecer diferencias a través de la geografía de los cuerpos, las texturas, crear una paradoja entre la fuerza de la existencia, la crudeza de la violencia; a la vez se sintió el impacto de esos cuerpos que se pasean desnudos a la vista de todos y que parecen mercancía que se compra y se vende como la vida de los que habitan estas ciudades. Durante el tránsito por las calles de Bogotá, la gente no pudo ocultar su asombro y la pregunta que retumbó fue: ¿están vivos? Más allá de la desnudez, la preocupación de quienes contemplaban la escena era vital. La performance recorrió la ciudad por un lapso de 4 horas y $30 \mathrm{~min}$, y llegó a la plaza Bolívar que es uno de los lugares más significativos de la capital. Para lograr la permanencia de los performistas se hizo un entrenamiento de más de tres meses, talleres con la comunidad, charlas, foros, trabajo de investigación sobre la violencia en Colombia.

La performance "Deborar" nace como respuesta al creciente número de feminicidios que ocurren en el país. Se inicia un laboratorio haciendo referencia a una de las pintoras más importantes del país: Débora Arango (1907-2005), y su descontento frente a las políticas del país, el papel de la mujer en Colombia en el siglo XX y otros temas álgidos para la idiosincrasia colombiana. De la artista se escoge el cuadro "Esquizofrenia en la cárcel” y se invitan a 12 mujeres del semillero de investigación, para hacer un proceso de investigación, entrenamiento e indagación sobre su feminidad y la vulneración de sus derechos. Para la acción, se escriben a lo largo de las piernas y en sus ropas interiores frases referidas al empoderamiento de sus cuerpos, mientras se paran en los parques con sus muslos ligeramente abiertos; se le entrega a la comunidad asistente un palo para tomar selfies en el que hay un espejo con el propósito de inspeccionar el cuerpo de las mujeres. Esta performance crea muchas reacciones e incluso algunos hombres las insultan y miran con morbo sus partes íntimas. 
FIGURA 2 - PERFORMANCE CARGA-MONTÓN
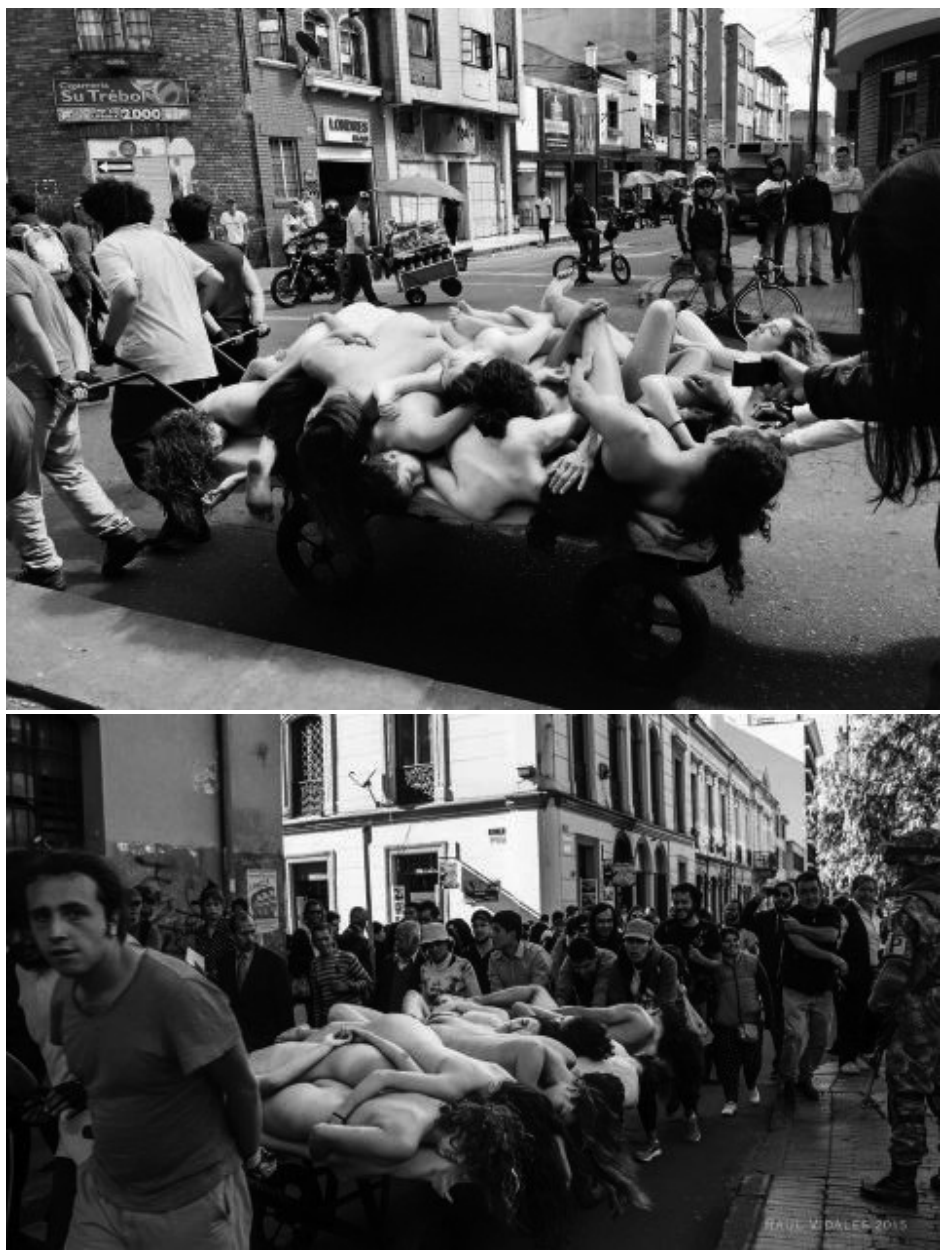

FONTE: Performance “Carga-Montón”. Colectivo Artístico El Cuerpo Habla. Bogotá, Colombia 2015.

Fotografías: Gabriel Mario Vélez S. 
FIGURA 3 - PERFORMANCE "DEBORAR"
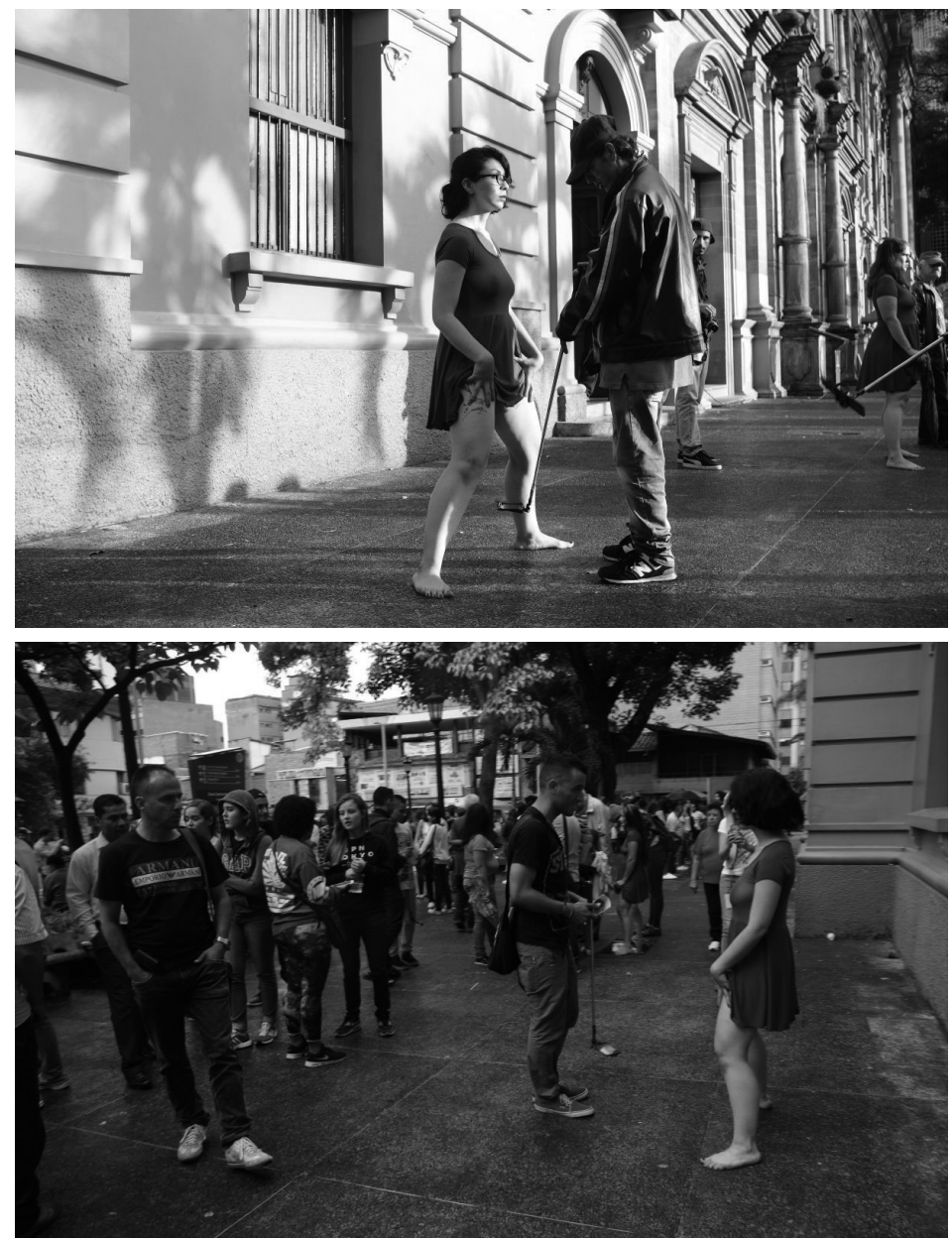

FONTE: Performance "Deborar”. Colectivo Artístico El Cuerpo Habla. Medellín, Colombia 2017. Fotografías: Edison Vásquez

"In-movedizo" es la propuesta de la estudiante de maestría que participó en la investigación y quien, además, es bailarina; ella establece una pregunta por el movimiento cotidiano, el detenerse, lo micro-social y lo político, las redes que se tejen alrededor de nosotros mismos y de la sociedad; cómo todos somos partícipes y creamos hilos invisibles que nos acercan y a veces nos cercan. La performance propone una danza desde la lentitud, la respiración, la relación 
con el espacio, con el tiempo y la conciencia del movimiento. La puesta en escena se realiza en la calle para integrar al espectador y permitirle una pausa; crearle un obstáculo para que piense en su cuerpo y su reacción frente al azar, al acontecimiento que surge inesperadamente.

\section{FIGURA 4 - EXPERIMENTACIONES PARA PERFORMANCE "IN-MOVEDIZO"}

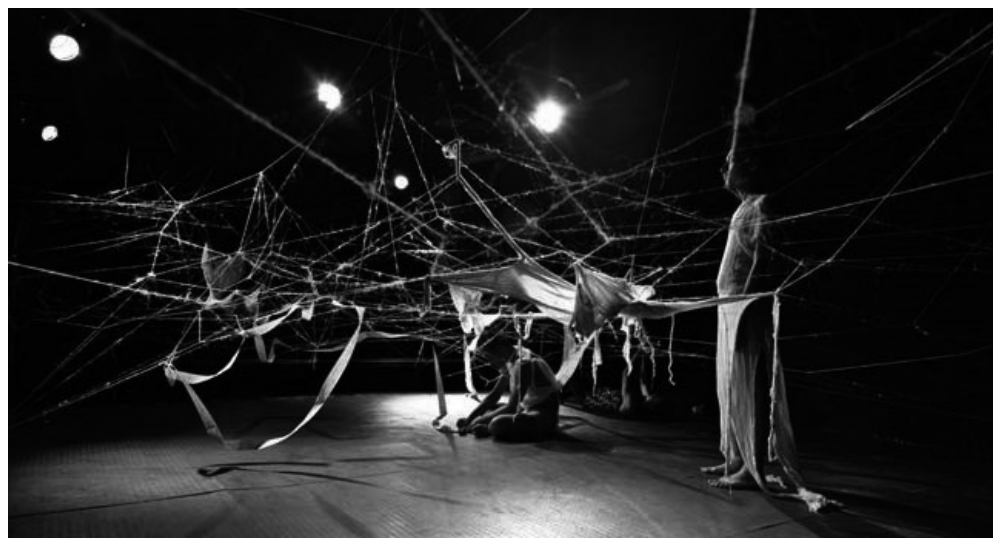

FONTE: Experimentaciones para performance "In-Movedizo". Medellín, Colombia 2017. Fotografía: Gustavo Villegas

\section{FIGURA 5 - PERFORMANCE "IN-MOVEDIZO” EN ESPACIO PÚBLICO}

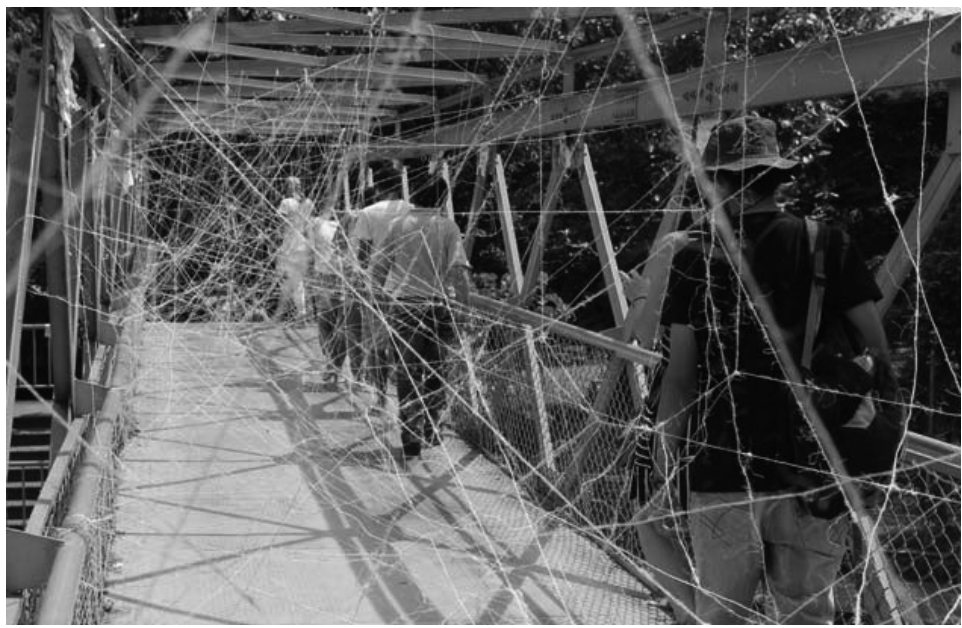

FONTE: Performance "In-Movedizo" en espacio público. Colectivo Artístico El Cuerpo Habla. Medellín, Colombia 2017.

Fotografía: Edison Vásquez 
"Hervir", "Con guerra no brazos", son ejercicios performativos que surgieron a partir de la asignatura Taller complementario El Cuerpo Habla, recibido por los estudiantes de artes, donde la consigna tiene que ver con el hecho de estar juntos, crear una acción desde el permanecer, el reconocimiento del cuerpo como potencia, quebrar el lugar de la representación como una alternativa. Se busca un forzamiento para lograr otros estados de conciencia, devenir animal, vegetal, tierra, agua, es decir, mundo, y el rompimiento de la identidad impuesta como categoría. En la clase, los estudiantes tienen la libertad de elegir sus ejercicios y el docente actúa como un acompañante más que como un director.

La pedagogía del acontecimiento que propone el Taller está en resonancia con el rizoma, las subjetividades, la fabulación. Se produce en el azar, en lo indexical, en el encuentro de una comunidad con su propio deseo; es por ello que se trabaja en colectivo. Dice Deleuze (1990), que no se hace arte con recuerdos, sino con devenires. Los afectos son devenires no humanos del hombre, y los perceptos son los paisajes no humanos de la naturaleza. No se está en el mundo, se deviene mundo y por ello se hace arte. Para esto, más que memoria, se producen sensaciones, tales como observar, seducir, estar pendientes del universo y de los cambios, entender que el control de la vida no es una tarea de lo humano. Se opta, entonces, por una pedagogía que haga de la vida una obra de arte, en la cual el cuidado de sí y del otro, sean pilares fundamentales. Se estimula una pedagogía del asombro, del nomadismo, que no se quede en el aula de clase, sino que salga a la calle como lugar del riesgo, del encuentro con la vida y el azar.

Una construcción colectiva implica la escucha, entender los actos de habla de una comunidad. La propuesta pedagógica se conjuga a través de cartografías, término que se deriva del trayecto más que del proyecto, acciones más que representaciones y mapas de viaje, los cuales estimulan la experiencia de nuevos componentes, de relaciones, territorios y máquinas. En el texto Mil mesetas (2002), Deleuze y Guattari cuestionan las maneras en las que el concepto de mapa se ha resuelto en Occidente, donde prevalece un pensamiento hegemónico, e invitan a la construcción de cartografías a manera de rizomas. Las cartografías sustentadas por estos autores sustituyen la centralidad, posicionan el deseo, deconstruyen el modo de pensamiento erigido por los sistemas de poder y las formas de producción social, multiplican las singularidades y por lo tanto derivan en un contexto político en el que se privilegia el gesto, el trayecto por encima del dibujo, y la presencia por encima de la representación. La cartografía sitúa en un mismo plano elementos heterogéneos, cuestiona la idea de estructura, de sistema, se instaura como una estrategia y no como un modelo o un método cerrado. Así mismo se busca que la acción sea amplia y abierta, para que intervengan varias cosas: el permanecer, el otro, el espacio, el 
tiempo; una mirada que abarque varios frentes, de manera que no haya un objetivo absoluto que cumplir y que se pueda estar atento al trayecto, a lo que está en el camino, para olvidarse del sí, del miedo, del dolor o al menos ser capaces de transformarlos. Se alteran los órdenes y las jerarquías; por esto no hay un director que diga qué hacer, sino un acompañante que puede abrir referentes, dar elementos de discusión, aportar desde su experiencia.

En aras de garantizar estos escenarios se hacen trabajos de investigación, lecturas, exposiciones, laboratorios, talleres, experimentaciones, viajes etc., para lograr un diálogo, que permita la circulación de saberes. Las ideas se ventilan, se cuecen colectivamente, se hacen ajustes para que el trabajo sea apropiado a las geografías de los cuerpos, la relación con el mundo, el espacio, el tiempo y los materiales.

En el Colectivo no hay una manera de ser de la carne, todos pueden ser viandantes y convidantes; las condiciones se dan en la medida de la exigencia de la performance, de la constancia, disciplina y disposición, la capacidad de asumir los retos, entrenarse, leer, estar atentos. El Cuerpo Habla está comprometido con la vida misma en lo que tiene de irrepresentable. Por esto, los temas de trabajo se recogen de las observaciones, de las problemáticas y dinámicas sociales, privilegiando este ejercicio grupal por encima de una pregunta individual. Esta última se absorbe en la necesidad de crear un deseo colectivo más que subjetivo, lo que implica ver lo social como una fuerza; se trata, entonces, de eliminar lo particular, para crear una manada como en la orgía y en el carnaval.

\section{REFERENCIAS}

Bergson, H. (1948). La evolución creadora, Madrid, España: Aguilar.

Bustamante, A. (2010). Los pliegues del sujeto, Madrid, España: Biblioteca Nueva.

Deleuze, G. (1987). ¿Qué es el acto de creación? Recuperado de: <https://gep21.files. wordpress.com/2010/02/deleuze-c2bfque-es-el-acto-de-creacion.pdf $>$. Acceso en: 3 abr. 2016.

Deleuze, G. (1987). La imagen tiempo estudios sobre cine 2. Barcelona, España: Paidós.

Deleuze, G. (1990). Conversaciones, Recuperado de: $<$ http://bibliotecaparalapersonaepimeleia.com/greenstone/collect/libros1/index/assoc/HASHa26a.dir/doc.pdf $>$. Acceso en: 18 mayo 2016.

Deleuze, G.; Guattari, F. (1993). ¿Qué es la filosofía?, Barcelona, España: Anagrama. 
Deleuze, G.; Guattari, F. (2002). Mil Mesetas. Capitalismo y esquizofrenia, Valencia, España: Pre-textos.

Diaz, E. Recuperado de: <http://www.estherdiaz.com.ar/textos/deleuze.htm>. Acceso en: 4 abr. 2016.

Dubatti, J. (2003). El convivio teatral: teoría y práctica del teatro comparado, Buenos Aires, Argentina: Atuel.

Hernández, G. (2001). La vitalidad recobrada, un estudio del pensamiento ético de Bergson. México D. F., Facultad de Filosofía y Letras. Universidad Autónoma de México.

Lacan, J. (2009). Escritos II, México D. F., México: Siglo XXI editores.

Lacan, J. (2015). El seminario VI, el deseo y su interpretación, Buenos Aires, Argentina: Siglo XXI editores.

Zunino, P. A. (2012). Inteligencia y superstición en Bergson: la función fabuladora. Intus-Legere Filosofia, v. 6, n. 1, p. 9-18. Recuperado de: <file://C:/Documents\%20 and\%20Settings/Angela/Mis\%20documentos/Downloads/Dialnet-InteligenciaYSupersticionEnBergson-4510532\%20(5).pdf>. Acceso en: 2 jun. 2016.

Texto recibido en 30 de octubre de 2017. Texto aprobado en 31 de octubre de 2017. 